\section{Aurora Borealis, Terrestrial Magnetic Disturbances, and Sun-spots.}

IN connection with the aurora borealis observed by Major Lockyer on September 28-29 (NaTure, October 6), there was a magnetic disturpance of considerable activity necorded at this observatory. It commenced at r2h., September 28. There were minor movements: on the $\mathrm{H}$ magnet, $\mathrm{D}$ remainirfg quiet, until a: more active phase of the disturbance commenced about Igh., September 28 . The major movements on all three magnets, $\mathrm{D}, \mathrm{H}$, and $\mathrm{V}$, took place between $1 \mathrm{~h} .36 \mathrm{~m}$. and $4 \mathrm{~h}$. $50 \mathrm{~m}$., September 29 . The extreme ranges on the curves were $\mathrm{D} 30^{l}, \mathrm{H} 82 \gamma$, and $\mathrm{V} 85 \gamma\left(\gamma \equiv \mathrm{I0}^{-3}\right.$ C.G.S. units). The mean daily ranges, for comparison, for the quiet days of September were D $\tau^{\prime}$, H $36 \gamma$, and $\mathrm{V}$ II $\gamma$.

The only spot on the sun on September $28-29$ was of moderate size, in latitude +8.5 and longitude $56 \cdot 0$, and it was approaching the sun's western limb. But on September 28 the longitude of the central meridian of the sun was $354 \cdot \mathrm{I}^{\circ}$. This gives the clue to the probable origin of the magnetic disturbance which accompanied the aurora, for the position is very near the longitude of the following spot of the great group of last May, namely, $35^{8} \cdot 8^{\circ}$, which on its passage across the sun's disc was connected with the series of magnetic disturbances of great violence. These, with a lull on May 18 , persisted from May 12 to May 2I. This spot-group was on the sun's equator, and also crossed the central meridian on May $14-15$ (Nature, June 2, p. 426).

It appears to be most likely that this region of the sun has remained magneticaliy active since the series of violent storms of May 12-2x. For we get the following sequence of magnetic disturbances, at intervals of 27 or 28 days, corresponding to the period of the sun's synodic rotation:-May I2-2 I, v.v. great; June 6-1o, great; July $7-9$, moderate, August $3-5$, great ; September 2, v. great; and September $28-29$, v. great.

The magnets have also been considerably disturbed on the early days of the present month of October, especially on October 5 and October 8. Meanwhile, the sun has been practically spotless. But here, again, with regard at least to the disturbance of October 5 , there is a sequence of disturbances corresponding to the synodic rotation period of the sun, which probably has its origin in the later phases of the violent storm of May. The sequence is :-May $2 \mathrm{I}$, moderate; June 18, calm; July I5, moderate; August II, moderate; September 8, great; and October 5, v. great. It will be noticed that in this sequence the magnets were quiet, and activity was in abeyance on June 18.

Since the violent storm of May there have been in all, until October 8,28 moderate, 2 great, and 4 very great disturbances. All these disturbances, except four marked moderate, fall into four series corresponding to the synodical rotation of the sun, and of these, again, 12 moderate, 2 great, and 3 very great belong to the two series alreadv discussed. It would, therefore, be premature to conelude, from the absence of sun-spots or other surface phenomena of the sun, when a magnetic disturbance occurs, that there is only a casual connection between sun-spots and terrestrial magnetic disturbance. An area on the sun may seemingly remain continuously or recurrently active for several solar rotations, even after the disappearance of the original solar disturbance. Or it may be that clouds of electrons discharged from a very active region on the sun remain undiffused for a considerable period. At the same time it is not evident why the magnetic activity should sometimes actually increase after a lull succeeding the original violent dis- turbance. Possibıy spectro-heliograms in calcium light may help to elucidate the subject.

A. L. Cortie.

Stonyhurst College Observatory, October I4.

\section{Sex-change in the Native Oyster.}

DR: ORTON's letter on the above subject published in Nature of July 7 , which I have just seen, touches a matter not only ot great biological interest, but also of marked importance in the economy of oyster fisheries. I can contirm the presence of spermmoru $x$ in oysters which are functioning as "whitesick" females, and also the observation that on being placed in sea-water the sperms appear to be fully ripe. There are, however, a large number of oysters, apparently the majority, in any fair sample which may be examined at the breeding season which show no advanced female elements, but are functioning solely as males. These oysters, so far as I have been able to notice, do not show signs of any rapid sexchange.

When one reflects that oysters are naturally found in beds, and that fertilisation requires the free passage of sperms through the water to impregnate functioning females-if we are to discard Lacaze-Dutier's idea of self-fertilisation-it seems inevitable that there is an immensely greater loss amongst the male than amongst the female elements, and the presence of an excess of males seems explained. In the same way the development of active sperms in the gonads of oysters which are already bearing fertilised embryos in their mantle cavities may be a provision to further augment the supply of sperms. The annual breeding period-physical conditions being favourable-is spread over a considerable interval in this country. During the past summer, for instance, free-swimming spat could be found early in June, yet I found oysters with black spat on July 20 , and "white-sick" oysters as late as. August 26 . In that period, it seems probable, from Dr. Orton's observations, that individual oysters may have functioned first as female and then as male shellfish. It would be very interesting to learn, however, if in the Plymouth observations any oysters functioning first as males showed any signs of ripening into females. The annual change of sex which Dr. Orton refers to as possible may be only in those oysters which are first predominantly female in sex. W. L. CALDERWOOD.

Edinburgh, October i4.

\section{A Relation: between the Combined Atomic Volumes and their Optical Refractivities.}

IT has been shown ("Morrograph on Molecular Volumes," Longmans, I917) that there is a periodic relationship between the atomic volumes of the combined elements. The submultiple $3 \cdot 6$, which is the atomic volume of combined hydrogen, has been found significant.

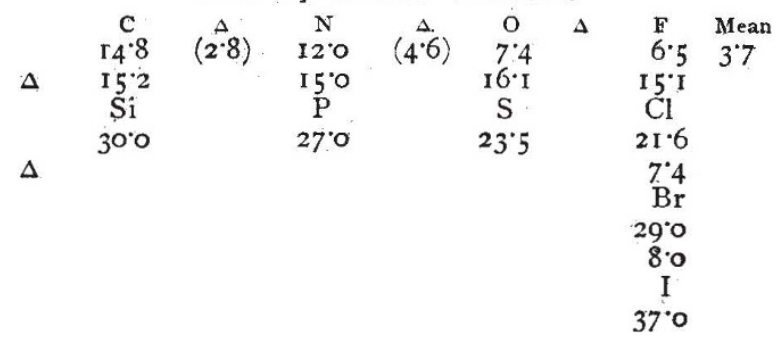

$\mathrm{I}, \mathrm{N}$, and $\mathrm{S}$, mean values. 